九州大学学術情報リポジトリ

Kyushu University Institutional Repository

\title{
Genetic Structure Analysis of Northeast Asian Sika Deer (Cervus nippon) Populations using Mitochondrial and Microsatellite Markers
}

YUN, Chi Sun

Division of Animal and Dairy Science, College of Agriculture and Life Science, Chungnam National University

CHUN, Ju Lan

Division of Animal and Dairy Science, College of Agriculture and Life Science, Chungnam National University

YU, Jung

Division of Animal and Dairy Science, College of Agriculture and Life Science, Chungnam National University

KIM, Dong Eon

Division of Animal and Dairy Science, College of Agriculture and Life Science, Chungnam National University

他

https://doi.org/10.5109/1909900

出版情報: 九州大学大学院農学研究院紀要. 63 (1)，pp.37-44，2018-02-27. Faculty of Agriculture， Kyushu University

バージョン :

権利関係 : 


\title{
Genetic Structure Analysis of Northeast Asian Sika Deer (Cervus nippon) Populations using Mitochondrial and Microsatellite Markers
}

\author{
Chi Sun YUN ${ }^{1 * *}$, Ju Lan CHUN ${ }^{1 * *}$, Jung YU ${ }^{1}$, Dong Eon KIM ${ }^{1}$, Kang-Sun PARK ${ }^{1}$, Eun Young KIM ${ }^{1}$, \\ Ji Hye LEE ${ }^{1}$, Kwang Bae YOON ${ }^{2}$, Nobuhiko YAMAUCHI ${ }^{3}$, \\ Seung-Hwan LEE ${ }^{1}$ and Min Kyu KIM ${ }^{1 *}$
}

\author{
${ }^{1}$ Division of Animal and Dairy Science, College of Agriculture and Life Science, Chungnam National University, \\ 220 Gung-dong, Yuseong-gu, Daejeon 305-764, Republic of Korea \\ ${ }^{2}$ Inje county office, Environment Protection Division, Inje-ro, Inje-eup, Inje-gun, \\ Gangwon-do, Republic of Korea \\ ${ }^{3}$ Department of Animal and Marine Bioresource Science, Faculty of Agriculture, \\ Kyushu University, Fukuoka, Japan \\ (Received October 19, 2017 and accepted November 20, 2017)
}

\begin{abstract}
The endemic species of sika deer in South Korean, $C$. n. hortulorum is classified as an endangered species. South Korea government has been attempted to restore the population of sika deer by importing and breeding. However, there has not been a sufficient study about the native and reintroduced sika deer in South Korea yet. The objective of this study was to investigate the phylogenetic relationship and genetic structure of sika deer in South Korea compared to those in other countries at Northeast Asia. We used 183 samples of sika deer from South Korea, Russia, China and North Korea. Mitochondrial DNA (mtDNA) cytochrome b (cyt b) was used to identify subspecies, and eleven of microsatellite markers were applied for genetic distance and structure analysis. The phylogenetic tree analysis confirmed that the origin of reintroduced subspecies in South Korea is C. n. taiouanus (Taiwanese subspecies) and C. n. yesoensis (Japanese subspecies). Genetic distance analysis using microsatellite markers showed that the South Korean sika deer differed from those in other countries. Sika deer in Russia and North Korea showed similarity. In addition, sika deer in North Korea has been protected and estimated as C. n. hortulorum that would allow to imply the native sika deer species in South Korea which has been extinct. In conclusion, sika deer reintroduced to South Korea would be originated from Japanese and Taiwanese subspecies and C. n. hortulorum would be the indigenous species.
\end{abstract}

Key words: Genetic structure, Mitochondrial DNA cytochrome b, Microsatellite markers, Phylogeny, sika deer (Cervus nippon)

\section{INTRODUCTION}

Sika deer is characterized by white spots and belongs to the family Cervidae. Thirteen subspecies of sika deer have been described including $C$. n. hortulorm, $C$. $n$. mandarinus, C. n. mantchuricus and C. n. sichuanicus that are distributed throughout Northeast Asia like North China, East Russia and Korean Peninsula (Wilson and Reeder, 2005). C. n. hortulorm and C. n. mantchuricus are known as the endemic species on Korean Peninsula. However there is argument that $C$. $n$. hortulorm and $C$. $n$. mantchuricus are the same subspecies and their statue of existence is unclear at present (Ba, et al., 2015; McCullough, 2009; Woon, 1967).

Sika deer is categorized as Least-concern species by the International Union for Conservation of Nature and Natural resources (IUCN) Red List because the population of them has been growing and stable in Japan and Russia. However, sika deer in South Korea and China has been classified as an endangered species, and C. n. gras-

* Corresponding author: Min Kyu Kim, DVM, Ph. D; Address: 99 Daehak-ro (st), Yuseong-gu, Daejeon, 305-764, Republic of Korea, E-mail: kminkyu@cnu.ac.kr; Tel: +82-42-821-5773; Fax: +82-42-825-9754.

** Chi Sun Yun and Ju Lan Chun contributed equally to this work. sianus and $C . n$. mandarinus are especially known to be already extinct in China (Harris, 2015). The native sika deer of South Korea has become also extinct due to destruction of habitat by over-exploitation and indiscriminate hunting after the Japanese colonial period and the Korean War. In North Korea, it is presumed that indigenous species of sika deer still exist because their government limited sika deer hunting and implemented a captive breeding program right after Korea War. However the genetic information of sika deer, which has been bred in North Korea, is limited (Jin, 2013; McCullough, 2009). Since the 1970s, South Korea government had banned deer hunting and implemented restoration programs of sika deer to enhance their population growth. On the other hand, South Korea government imported Japanese and Taiwanese sika deer to domesticate them and use in exhibition and produce deer antler rather than restoring and maintaining endemic species that would enhance the extinction of native sika deer in South Korea (Jin, 2013; Koh, et al., 2010).

Genetic analysis of sika deer in South Korea has been conducted by mitochondrial DNA analysis. It was reported that they are $C$. $n$. taiouanus (Taiwanese species) and C. n. yakushimae, (Japanese species) respectively. However, it is suggested that mtDNA analysis might be incomplete lineage sorting to identify sika deer species (Koh, et al., 2010; Kwon, 2010; Lee, et al., 2016). 
Furthermore, it has not been known that genetic relationship of sika deer in South Korea and Northeast Asia.

The purpose of this study is to identify the subspecies of sika deer reintroduced in South Korea and to investigate the genetic relationship of sika deer among different populations in other countries at Northeast Asia including North Korea. Therefore we analyzed the population parameters of sika deer in South Korea compared to those in Russia, China and North Korea to investigate their phylogenetic relationship and genetic structure using both mtDNA and microsatellite markers.

\section{MATERIALS AND METHODS}

\section{Sample collection}

Hair, tissue and blood samples were collected from 183 sika deer in four countries; South Korea (National Institute of Biological Resources and Inje-gun, $\mathrm{N}=70$ ), Russia (Conservation Genome Resource Bank for Korean Wildlife, $N=19$ ), China (Yanbian farms and Chinese Academy of Agricultural Sciences, $\mathrm{N}=40$ ) and North Korea (Majeon, Kimhyonggwon, Suncheon and Samcheon farms and Pyongyang Central Zoo, N = 54). All samples were sealed in plastic bags or blood tube and preserved at $-4^{\circ} \mathrm{C}$ until DNA extraction.

\section{DNA extraction and amplification}

DNA extraction was conducted using DNeasy ${ }^{\circledR}$ Blood \& Tissue Kit (QIAGEN, USA) and followed a Quick-start protocol included with the kit. More than 50 strands of hair samples were used to extract DNA for each individual. Whole genome amplification was conducted using REPLI-gMini Kit (QIAGEN, USA) for DNA quantity amplification and purification.

\section{mtDNA amplification and phylogenetic analysis}

Cyt b as a mtDNA marker was selected to estimate the phylogenetic relationship. Cyt b amplification was performed using primers; forward A (5'-tctcacatggaatctaaccatgact-3'), forward B (5'-tacacttactcttccttcacgagac-3'), reverse A (5'-cgtgggggtgtggctatgc-3') and reverse B (5'-ggctggggacccaccacctgtg-3'). PCR reaction mixture was in volume of $50 \mu \mathrm{L}$ contained PCR primer mix $2 \mu \mathrm{L}, 10$ X buffer $5 \mu \mathrm{L}$, dNTP $5 \mu \mathrm{L}$, Taq $1 \mu \mathrm{L}$, templet DNA $50-100 \mu \mathrm{g}$ and sterilized distilled water up to $50 \mu \mathrm{L}$. PCR amplification was conducted as follows: an pre-denatureation step of 5 min at $95^{\circ} \mathrm{C}$, followed by 40 cycles of denaturation step of $30 \mathrm{sec}$ at $95^{\circ} \mathrm{C}$, annealing at $62^{\circ} \mathrm{C}$ for $45 \mathrm{sec}$, elongation at $72^{\circ} \mathrm{C}$ for $60 \mathrm{sec}$, and final extension at $72^{\circ} \mathrm{C}$ for $10 \mathrm{~min}$. The PCR products were purified using EtOH precipitation method as follows: the mixture of PCR products $50 \mu \mathrm{L}, 3 \mathrm{~N}$ NAOAC $5 \mu \mathrm{L}$ and $100 \%$ EtOH $125 \mu \mathrm{L}$ was centrifuged and stored at $-20^{\circ} \mathrm{C}$ until sequencing mtDNA. mtDNA sequences were analyzed by Bioneer (Daejeon, Korea) and alignment was performed using BioEdit v.7.0.1 (Hall, 1999). Each subspecies of sika deer was classified by cyt b sequences $(1,140 \mathrm{bp})$. The phylogenetic analysis was performed based on sika deer genomic DNA sequences registered GenBank Database. Sika deer haplotypes ( $C$. n. kopschi, JN389444, HQ832482; C. n. sichuanicus, JN389443; C. n. taiouanus, DQ985076, EF058308; C. n. hortulorum, GU457433, HQ191428; C. n. yesoensis, AB021095, AB201267; C. n. nippon, JF893469 and JF893473) were used including Cervus canadensis xanthopygus (GU457434) as an outgroup comparison. The phylogenetic relationships among sika deer subspecies were analyzed. To make systemic family tree, neighbor-joining tree basis of Tamura-Nei's genetic distance method was applied which was an unrooted method by Mega 5.1 program.

\section{Microsatellite loci amplification}

The microsatellite analysis was conducted using 5 Odocoileus henionus (C01, C105, C143, C180 and C229) and 6 Cervus elaphus (C02, C32, C36, C273, T40 and T107) markers (Supplementary Table S1 online). The PCR reaction mixture contained PCR primer mix $2 \mu \mathrm{L}, 10 \mathrm{X}$ buffer $5 \mu \mathrm{L}$, dNTP $5 \mu \mathrm{L}$, Taq $1 \mu \mathrm{L}$, template DNA 50 - $100 \mathrm{ng}$ and desterilized distilled water up to $50 \mu \mathrm{L}$. Each forward primer was labeled with fluorescent dyes (6-FAM, VIC, NED, PET and LIZ). PCR was performed in 40 cycles of denaturation for $30 \mathrm{sec}$ at $95^{\circ} \mathrm{C}$, annealing for $45 \mathrm{sec}$ at $62^{\circ} \mathrm{C}$, elongation for $60 \mathrm{sec}$ at $72^{\circ} \mathrm{C}$, and final extension at $72^{\circ} \mathrm{C}$ for $10 \mathrm{~min}$. PCR products were analyzed by Genemapper 3.7 software.

\section{Genetic distance and population structure analysis}

The genetic distances for phylogenetic analysis based on Nei's distance methods were calculated using the PowerMarker ver. 3.25 program and visualized using Mega 5.1 program with the bootstrap number was 1,000. The STRUCTURE ver. 2.3.4 was used to analysis population structure and estimate the potential populations (K). The admixture model was used and run 20 replications of $\mathrm{K}$ ranging from 1 to 8 . A burin-in period was at 20,000 following 1,000,000 replicated of the MCMC. The $\Delta \mathrm{K}$ was calculated using formula:

$\Delta \mathrm{K}=\mathrm{m} / \mathrm{L}(\mathrm{K}+1)-2 \mathrm{~L}(\mathrm{~K})-\mathrm{L}(\mathrm{K}-1) \mathrm{l} / \mathrm{s}[\mathrm{L}(\mathrm{K})]$ (Evanno, et al., 2005).

\section{Hybridization}

Hybridization analysis was performed to identify the genetic composition of each individuals through a STRUCTURE based on 11 microsatellite loci. The criterion for each genetic composition was wet to be $>0.90$, and individuals with a genetic composition of over 0.90 were regarded as 'pure' individuals. When the mainland Asian haplotypes were set as one cluster and analyzed as $\mathrm{K}=4$ (C. n. hortulorum, C. n. taiouanus, C. $n$. yesoensis and mainland Asian subspecies), and there was no individuals for $>0.90$ in one cluster. Therefore, the set of $\mathrm{K}$ value was decided at 3 .

\section{Statistical analysis}

The phylogenetic analysis using mtDNA cyt b was calculated by Mega 5.1 program. The genetic distances and phylogenetic analysis using microsatellite markers were conducted by PowerMarker ver. 3.25 program. Structure analysis and hybridization analysis were per- 
formed using the STRUCTURE ver. 2.3.4.

\section{RESULTS}

\section{Identification of sika deer species using mtDNA}

To investigate phylogenetic relationship, mtDNA sequences which had been published on GenBank were analyzed and used to draw phylogenetic diagram. Twelve mtDNA sequences of sika deer were categorized into six subspecies as shown in Fig. 1 and used to analyze taxonomic relationships of sika deer samples from four different countries (Fig. 2). In total, 183 samples of sika deer were classified into three subspecies including "Clade A" of which mtDNA sequences were matched

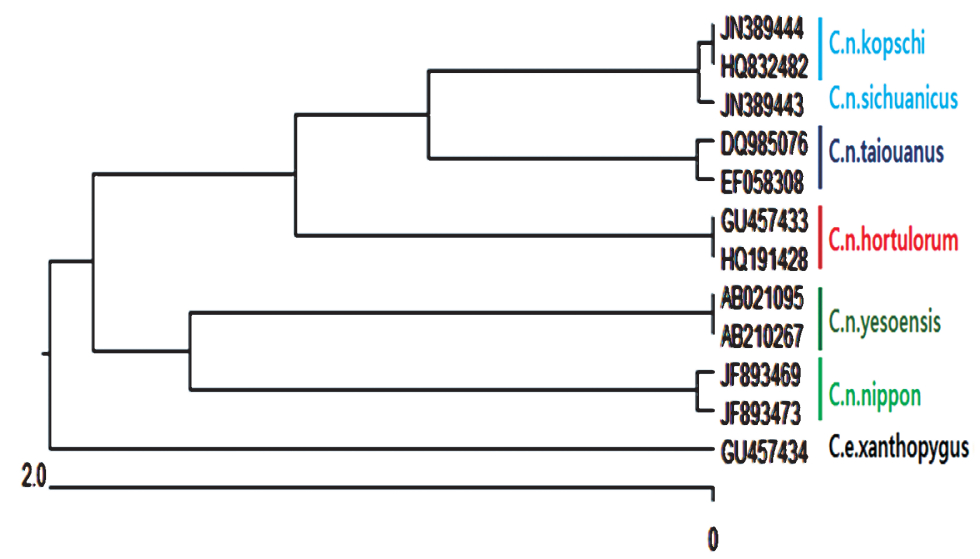

Fig. 1. The phylogenetic relationship among sika deer subspecies by mtDNA cyt b sequences. The sequences aligment was conducted by BioEdit ver. 7.0.1. Phylogenetic analysis was calculated using Nei's method by Mega 5.1 program. The criteria for genetic distance were shown at the bottom of diagram. Total 12 haplotypes of sika deer registered in GenBank were used and $C$. n. xanthopygus (GU457434) was used as outgroup. The color of each subspecies name indicated clades classification. Because C. n. kopschi and $C . n$. sichuanicus are the same mainland Asian subspecies, they were classified in the same color.

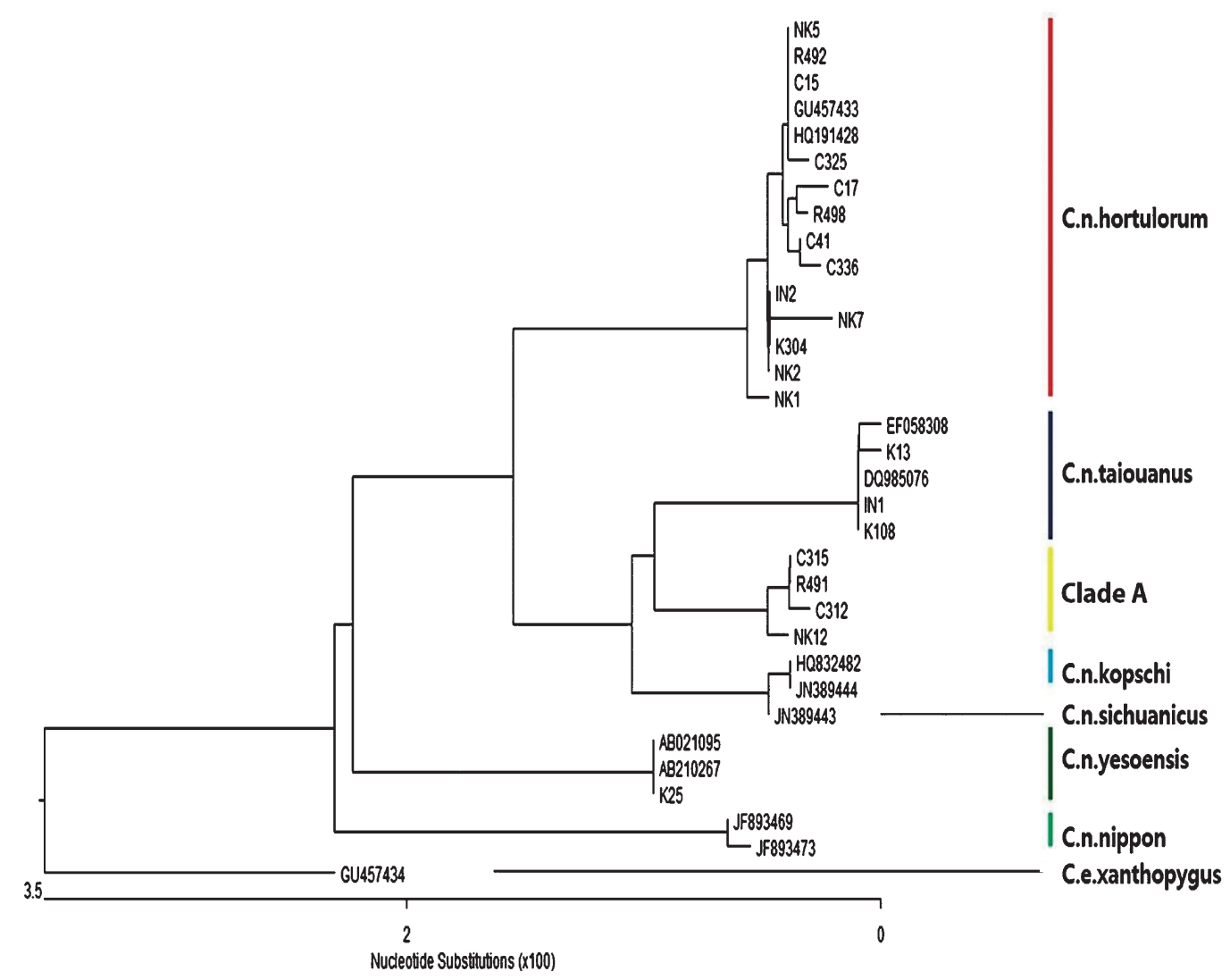

Fig. 2. Phyolgenetic relationship of 183 sika deer samples in four countries using mtDNA cyt b sequences. The sequences aligment was conducted by BioEdit ver. 7.0.1. Phylogenetic analysis was calculated using Nei's method by Mega 5.1 program. The analysis was performed using the 183 sika deer samples and 12 sika deer cyt b sequences used in Figure 1. The criteria for genetic distance were shown at the bottom diagram. The initials of the individual number refer to the source country of each sample: $\mathrm{K}$ and IN= South Korea, $\mathrm{R}$ = Russia, $\mathrm{C}=$ China and NK = North Korea. This does not showed the entire samples used in the analysis, but the analysis of each country was contained in Supplementary Fig. S1. A to D. Clade A was not grouped with specific subspecies haplotype and thus could not identify a definite subspecies. This population was referred to mainland Asian subspecies because it was associated with C. $n$. taiouanus, $C$. $n$. kopschi and C. n. sichuanicus. 
none of those in PubMed data base. 70 samples of sika deer in South Korea were found to be belonged to $C$. $n$. taiouanus, C. n. yesoensis and C. n. hortulorum (Supplementary Table S2). The Russian, Chinese and North Korean sika deer samples were belonged to $C$. $n$. hortulorum and Clade A that were grouped adjacent to C. n. taiouanus, C. n. kopschi and C. n. sichuanicus (Fig. 2 and Supplementary Table S2).

\section{Evaluation of genetic distance among sika deer populations}

Using microsatellite DNA, genetic distance of each sika deer population in four countries was investigated by Nei's unbiased genetic distance analysis (Table 1).
The average genetic distance was 0.1016 and the populations of sika deer in Russia and North Korea showed the lowest genetic distance value with 0.0597. The larg-

Table 1. Genetic distance among Northeast Asian sika deer populations

\begin{tabular}{ccccc}
\hline Population & China & $\begin{array}{l}\text { North } \\
\text { Korea }\end{array}$ & Russia & $\begin{array}{l}\text { South } \\
\text { Korea }\end{array}$ \\
\hline $\begin{array}{c}\text { China } \\
\text { North Korea }\end{array}$ & 0.111 & 0 & & \\
Russia & 0.0937 & 0.0597 & 0 & \\
South Korea & 0.1125 & 0.1333 & 0.0995 & 0 \\
\hline
\end{tabular}

A.

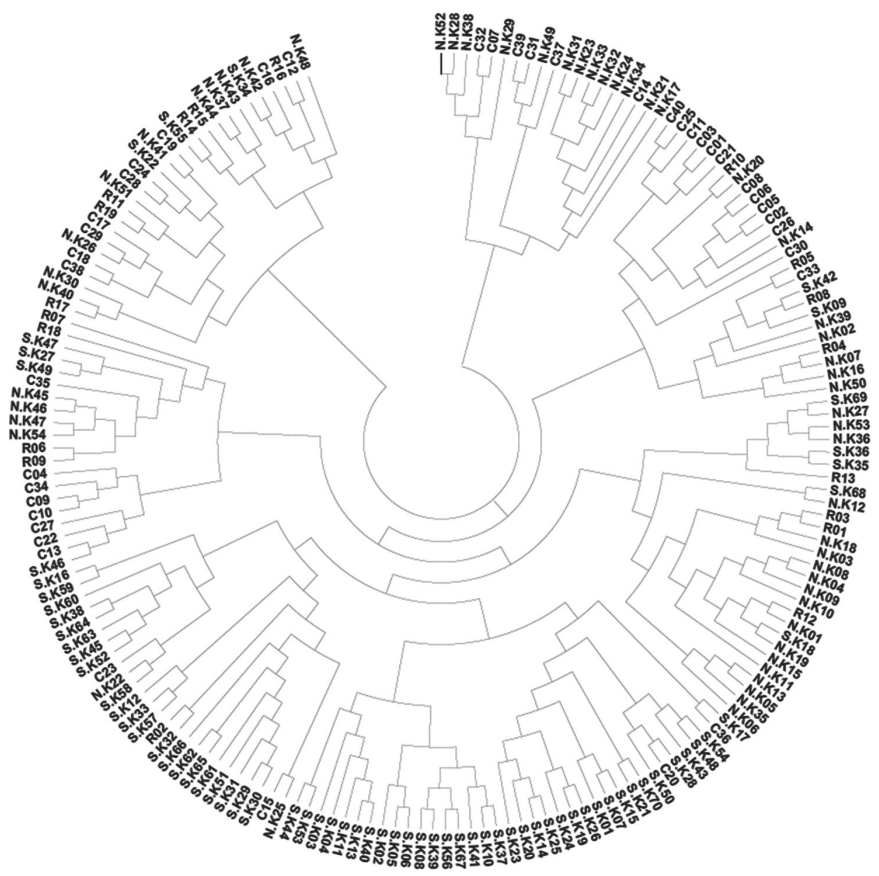

B.

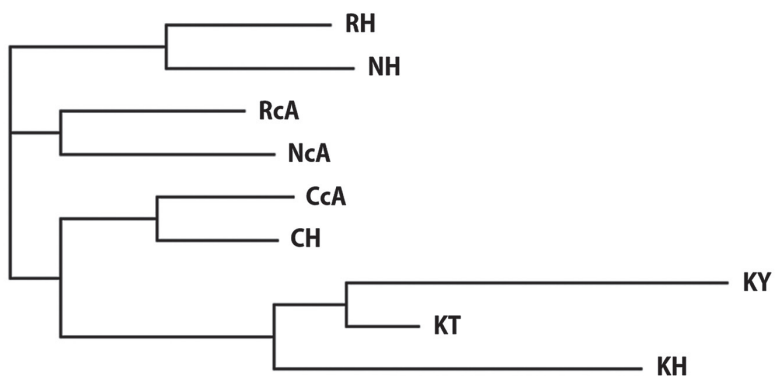

$\stackrel{\longrightarrow}{\longrightarrow}$

Fig. 3. Phylogenetic analysis of sika deer samples in four countries using 11 microsatellite markers. A. Phylogenetic analysis based on Nei's distance among each individuals. A samples of 183 genetic distance was calculated using Nei's method by PowerMarker ver. 3.25. The tree method used neighbor-joining method, and the bootstrap number was 1,000. The initials of the individual number refer to the source country of each sample: S.K = South Korea, R = Russia, C = China and N.K = North Korea. B. Phylogenetic relationship among subspecies groups in each countries. The genetic distance of each subspecies groups in each country was calculated using Nei's method by PowerMarker ver. 3.25. Each subspecies groups were classified on the basis of subspecies and clade which identified by mtDNA analysis and country. The criteria for genetic distance were shown at the bottom diagram. The initials represent the subspecies groups of each country: $\mathrm{KY}=$ South Korean $C$. $n$. yesoensis, KT $=$ South Korean C. $n$. taiouanus, $\mathrm{KH}=$ South Korean C. $n$. hortulorum; $\mathrm{RH}=$ Russian C. n. hortulorum, RcA= Russian Clade $\mathrm{A} ; \mathrm{CH}=$ Chinese C. $n$. hortulorum, $\mathrm{CcA}=$ Chinese Clade A; $\mathrm{NH}=$ North Korean C. $n$. hortulorum, $\mathrm{NcA}=$ North Korean Clade A. 
est value of genetic distance was between South Korean and North Korean populations (0.1333). Neighbor-joining tree based on Nei's unbiased genetic distance analysis visualized the relative genetic distance of 183 individuals (Fig. 3A). The individuals in the same country tended to locate in closed genetic distance and gathered together to forming groups. The populations of South Korea and North Korea were located far apart from each other in the phylogenetic tree. In addition, the genetic distance of each sika deer subspecies from four countries was applied and re-organized by mtDNA analysis (Supplementary Table S3). The largest genetic distance of $C$. n. hortulorum (NH) was 0.2081 when it was compared with South Korean C. n. hortulorum (KH). KH also showed relatively large values of 0.1704 0.1828 when it was compared with Russian C. n. hortulorum (RH) and Chinese C. n. hortulorum (CH). KH, South Korean C. n. yesoensis $(\mathrm{KY})$ and South Korean C. n. taiouanus (KT) groups were located adjacent to each other in phylogenetic tree although they were classified into different subspecies groups. $\mathrm{RH}$ in Russia was gathered together with $\mathrm{NH}$ and Russian Clade A formed a group with those in North Korea in phylogenetic tree. (Fig. 3B).

\section{Genetic similarity of sika deer populations based on genetic structure analysis}

Genetic structure analysis was performed with STRUCTURE to study whether sika deer from four countries were genetically different. The maximum value of $\Delta \mathrm{K}$ was observed when $\mathrm{K}$ was set to 2 (Supplementary Fig. S2). The STRUCTURE analysis was performed in the range of $\mathrm{K}$ from 2 to 8 (Fig. 4). According to the $\mathrm{K}$ value, most individuals appeared to be various hybridization. At $\mathrm{K}=2$, one of haplotype patterns superior in Russia, China and North Korea (green pattern), and other haplotype patterns were dominant in South Korea which was different from other countries (red pattern). The sika deer populations of Russia, China and North Korea had similar patterns of haplotype at $\mathrm{K}$ $=2$ to 4 . However different patterns of haplotype were prominent at $\mathrm{K}=5$ to 8 in North Korea.

\section{Genetic hybridization of sika deer in phylogenic tree}

STRUCTURE analysis was applied to distinguish individuals of sika deer which have the rate of 'pureness' which is clustering over 0.90 (Table 2). No individual with 'pure' ratio at a probability $>0.99$ was found so that 0.90 was used to set cluster criteria. There were 26 of C. n. hortulorum and 2 of Clade A in Cluster 1, 7 of $C$. n. hortulorum, 12 of $C$. n. taiouanus and 6 of $C$. $n$. yesoensis in Cluster 2, and 7 of $C$. n. hortulorum, 15 of C. n. taiouanus and 1 of Clade A in Cluster 3. In South Korea, 19 individuals were included in Cluster 2 and 16

Table 2. Clustering among sika deer from Korea, Russia, China and North Korea based on STRUCTURE $(>0.90)$

\begin{tabular}{cccc}
\hline Population & Cluster 1 & Cluster 2 & Cluster 3 \\
\hline South Korea & - & 19 & 16 \\
China & 8 & 5 & - \\
Russia & 1 & - & 2 \\
North Korea & 19 & 1 & 5 \\
Total & 28 & 25 & 23 \\
\hline
\end{tabular}

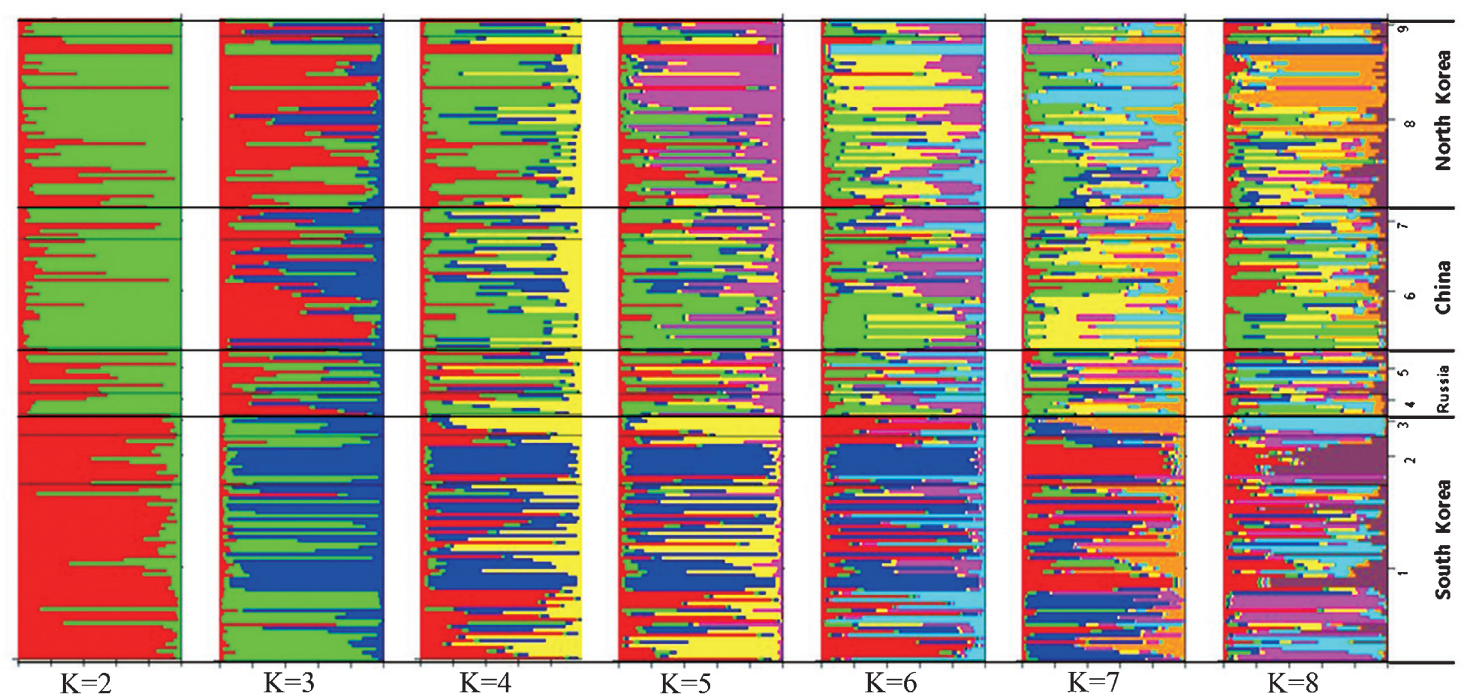

Fig. 4. STRUCTURE analysis among 183 sika deer samples using 11 microsatellite markers of $\mathrm{K}=2$ to 8 . The analysis was run 20 replications of $\mathrm{K}$ ranging from 1 to 8 with a burin-in period 20,000 and 1,000,000 replicated of the MCMC by STRUCTURE ver. 2.3.4. The genetic composition of each $\mathrm{K}$ value figure used in the diagram was randomly selected from among the 20 repeated analyzes. Black lines separate each populations and numbers indicates subspecies groups of each countries by mtDNA. South Korea: $1=$ C. n. taiouanus $(\mathrm{KT}), 2=$ C. n. yesoensis $(\mathrm{KY}), 3=C$. n. hortulorum (KH); Russia: $4=$ Clade A $(\mathrm{RcA}), 5=C . n$. hortulorum $(\mathrm{RH}) ;$ China: $6=C$. n. hortulorum $(\mathrm{CH}), 7=\mathrm{Clade} A$ (CcA); North Korea: $8=$ C. $n$. hortulorum (NH), $9=$ Clade A (NcA). Each bar plot represents the genetic composition of single individual.

Within a specific $\mathrm{K}$ value range, the same color pattern indicate the same haplotype 
A.

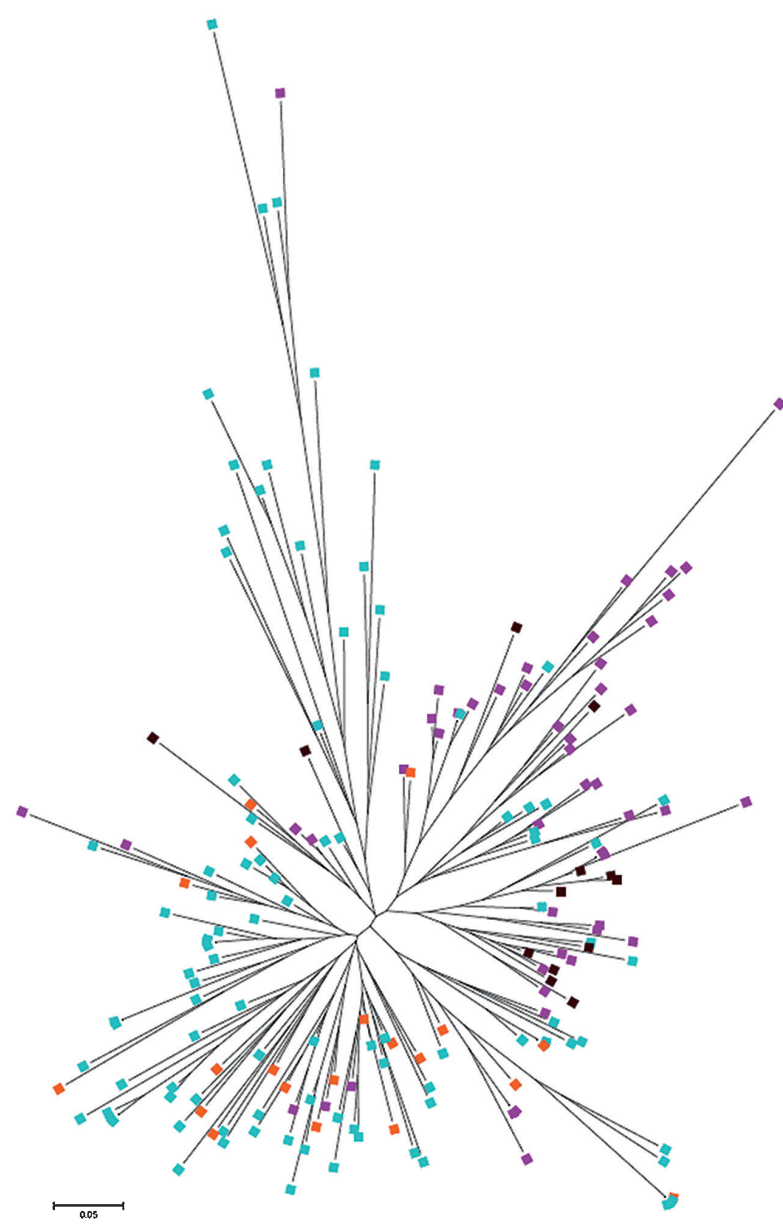

B.

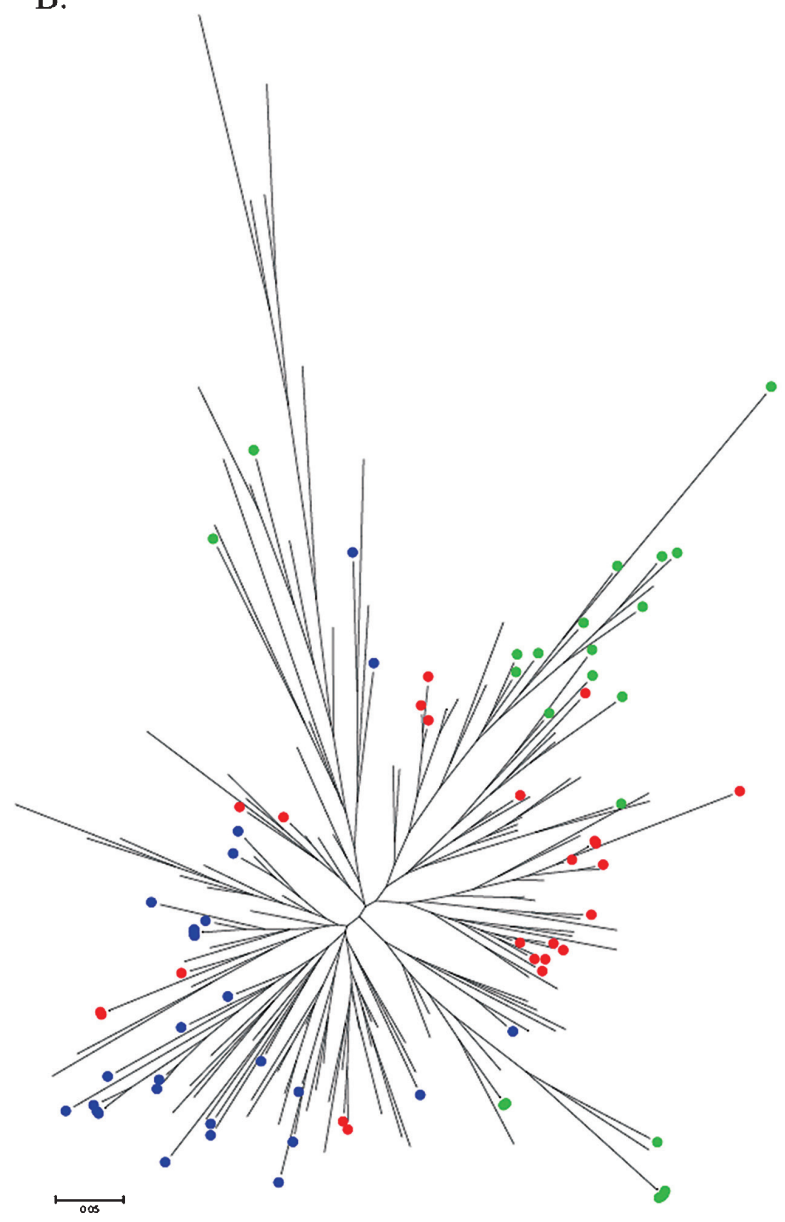

Fig. 5. Comparison of mtDNA and microsatellite markers analysis in phylogenetic tree. A. It was used mtDNA subspecies information in phylogenetic tree using microsatellite markers: sky blue $=$ C. $n$. hortulorum, Pink $=C$. $n$. taiouanus, Dark brown $=$ C. $n$. yesoensis. Orange = Clade A. B. It applied STRUCTURE analysis information to phylogenetic tree using microsatellite markers: Blue $=$ Cluster 1, Red $=$ Cluster 2, Green $=$ Cluster 3. The phylogenetic tree based on the microsatellite markers was calculated using Nei's method by PowerMarker ver. 3.25.

The criteria for genetic distance were shown at the bottom of diagram. Each phylogenetic tree was identical, and $\mathbf{A}$ indicated the subspecies of all individuals identified by mtDNA analysis in phylogenetic tree using microsatellite markers. B indicated only individuals with a specific pattern at $>0.90$ through STRUCTURE analysis using microsatellite markers.

individuals were in Cluster 3. However there was the largest number of individuals (19) in North Korea that were included in Cluster 1, and there were 1 individual in Cluster 2 and 5 individuals in Cluster 3. A few of sika deer in Russia was confirmed as 'pure' sika deer (3 out of $19 ; 15.8 \%)$. Thirteen individuals of Chinese population $(32.5 \%)$ were categorized as 'pure' sika deer, 8 of them belonged to Cluster 1 , and 5 of them belonged to Cluster 2. Subsequently, STRUCTURE data was used to draw phylogenetic tree and the location of each individual subspecies based on mtDNA were applied to the phylogenetic tree (Fig. 5A). Four subspecies individuals of C. n. hortulorum, C. n. yesoensis, C. n. taiouanus and Clade A were scattered in a wide range. However, when individuals of sika deer were applied to the phylogenetic tree made by STRUCTURE data based on clustering rates of $>0.90$ using microsatellite DNA analysis, there were individuals which were formed a number of clusters in adjacent location of phylogenic tree (Fig. 5B).

\section{DISCUSSION}

\section{Taxonomic identification}

The sika deer in South Korea and Japan were originated from more than a single lineage and formed different mtDNA lineages from Asian continent subspecies (Jo, 2015). It has been known that Japanese and Taiwanese subspecies of sika deer had been reintroduced into South Korea to restore the population of sika deer after its extinction (Jin, 2013). In this study, the analysis of mtDNA was used to identify the major subspecies of sika deer samples collected from South Korea, Russia, China and North Korea. Our result revealed that the populations of sika deer were classified into four different subspecies. The most of South Korean sika deer population formed clades with two subspecies haplotypes, $C . n$. taiouanus and $C$. $n$. yesoensis, that is the same subspecies with those in Japan and Taiwan and this was similar result to those from previous studies (Koh, et al., 2010; Kwon, 2010). 
C. $n$. hortulorum of sika deer has been considered to be almost extinct or have no relevant information (Harris, 2015). The population of Russian C. n. hortulorum had been declined and then reincreased during 1970 s to end of the 1980s because of the protection policy. Now, Russian C. n. hortulorum was also bred with other subspecies of sika deer from mainland Asia and Japan (Krojerova-Prokesova, et al., 2013). Here, we revealed the existence of $C$. $n$. hortulorum in South Korea, China and North Korea based on mtDNA sequences. Moreover, sika deer in North Korean farm had shown to be related with the sika deer population in Northeastern China (Koh and Jin, 2008). We confirmed that the most of sika deer in North Korean were grouped as $C$. n. hortulorum haplotypes and similar with Chinese and Russian populations. However, there is possibility that mtDNA analysis could not identify the hybridization of individuals, and it was observed that some of Russian population were grouped into Clade A which was made of mainland Asian subspecies, C. n. taiouanus, C. $n$. kopschi and C. n. sichunaicus.

\section{Genetic distance}

Genetic similarity can be calculated by Nei's unbiased genetic distance and phylogenetic analysis between each populations to estimate their relationship. Unlike the geographically adjacent location, sika deer populations in South Korea and North Korea had the largest genetic distance and were distributed far away from each other in the phylogenetic. In addition, genetic distance of $C$. n. hortulorum in South Korea was relatively apart when it was compared with those in other countries (Russia, China and North Korea). It implied that South Korean and North Korean populations of sika deer would be genetically separated and/or derived from different ancestors. Moreover, sika deer in South Korea and North Korea shared no direct correlation between genetic distance and subspecies, and it supported that the lineages of sika deer in South Korea and North Korea would be different. In previous report, subspecies of sika deer in China, Japan and Taiwan had distinct haplotypes and formed different clades in phylogenetic analysis ( $\mathrm{Lu}$, et al., 2006). Sika deer in Russia and North Korea had the lowest distance values which implied that North Korean and Russian populations originated from the same common ancestor, or until recently, there was an exchange between the two populations.

\section{Genetic structure}

Using mtDNA analysis, we confirmed that there were three sika deer subspecies and a group of sika deer with unidentified mtDNA sequences in South Korea, China, Russia, and North Korea which were formed different clades. We therefore expected that these three subspecies and the unidentified group would display different patterns and same subspecies would show same patterns in STRUCTURE analysis. However, the population of C. n. hortulorum in South Korea showed a different structure pattern from those in $C$. n. hortulorum populations from Russia, China and North Korea.
The association of the same subspecies in Korean and other countries populations is not clear. However individuals which have unidentified mtDNA sequences were related to the C. n. taiouanus in Russia, China, and North Korea, and showed different structure patterns from C. n. taiouanus in South Korea. It inferred that the populations of sika deer in South Korea would be separated from other countries quite a while ago or derived from other lineages. Even though Taiwanese sika deer was isolated from mainland China for about 10,000 years after landbridge was submerged (Wang, et $a l ., 1998)$, there was a record that $C . n$. taiouanus was also partly distributed in Southern China (Harris, 2015). With that, it would be possible that the similarity of $C$. $n$. taiouanus with Clade A individuals in Russia, China and North Korea could be the result of migration of $C$. $n$. taiouanus from Southern China to Northeast Asia. In addition, the different haplotype patterns among individuals of same subspecies would be the limited number of samples. The lack of samples in particular populations could cause an uncertain result in microsatellite marker analysis (Evanno, et al., 2005; Lee, et al., 2016).

North Korean and Russian populations of sika deer showed different structure patterns according to the $\mathrm{K}$ value despite closed genetic distance each other. It would be the result of isolation by border and farming even though North Korean and Russian populations had the same origin.

C. n. taiouanus and C. n. yesoensis have similar appearance like an average shoulder height and weight, and $C$. $n$. hortulorum is slightly larger than the other of two subspecies (Whitehead, 1993). However, there is a report that various breeding in different deer farm can cause changes in appearance (McDevitt, et al., 2009). Therefore the appearance alone would be not enough to distinguish each subspecies and as a result, hybridization between different subspecies could occurred. For example, $C . n$. yesoensis and $C . n$. hortulorum in South Korea showed different haplotype patterns, but $C$. $n$. taiouanus in South Korea shared similar patterns with both $C . n$. yesoensis and $C . n$. hortulorum in South Korea. In other countries as well, there were individuals that showed the similar patterns among different subspecies populations within their country. We therefore considered that the different subspecies populations within a country could showed similar haplotype pattern in STRUCTURE result.

\section{Genetic hybridization}

Sika deer in Northeast Asia except North Korea experienced various gene flows such as migration, introduction of wild population, and exchange between farms and conservation parks since the early 1900s (Aramilev, 2009; McCullough, et al., 2009; Wang, et al., 1998). With that, it is difficult to distinguish genetically pure sika deer regarding phenotypes. In addition, hybridization of red deer, sika deer and wapiti rarely occurred in the wild, but it is inevitable (Krojerova-Prokesova, et al., 2013; McDevitt, et al., 2009). Therefore it is possible that the analyzed sika deer samples would have been hybridized 
with various sika deer subspecies as well as different species. However, we could not determine exactly which species were mixed with our sika deer samples because we had not conducted a comparative analysis with other sika deer subspecies and other species that can hybrid with sika deer.

Analysis of mtDNA and microsatellite markers has been used to account for genetic relationships of species. In this study mtDNA was able to identify subspecies of sika deer, but could not determine the degree of hybridization of each individuals. Therefore, microsatellite DNA analysis was applied to draw the phylogenetic tree and it was able to determine the 'pure' individual information which were grouped into same clusters. Although there was no clear standard of genetic purity, it was definite that there were individuals with high genetic similarity to the specific subspecies haplotypes in North Korea, and they were highly correlated with $C$. n. hortulorum.

In conclusion, we showed that sika deer in South Korea would be subspecies which is imported from Japan and Taiwan. Sika deer in South Korea was also genetically different from Russian, Chinese and North Korean populations. The sika deer population in North Korea was identified as $C$. n. hortulorum, an indigenous subspecies in Northeast Asia that showed closed genetic relationship with Russian population. Sika deer in South Korea would be hybridized with other subspecies and Sika deer in North Korea is possible to be relatively 'pure' breed subspecies. Therefore it is possible that $C$. $n$. hortulorum would be the native sika deer species of South Korea. However, we could not confirmed which species or subspecies of sika deer were mixed with those in South Korea. In addition, mtDNA and microsatellite markers can be used together for more accurate genetic analysis. In the case of single analysis of mtDNA would be suitable to identify subspecies of individuals and microsatellite markers would be possible to use for categorizing individuals in populations according to residence area and breeding farm rather than subspecies identification.

\section{AUTHOR CONTRIBUTIONS}

Chi Sun Yun conceived of the presented idea, designed the experiment, carried out the experiment, and wrote the manuscript.

Ju Lan Chun conceived of the presented idea, designed the experiment, carried out the experiment, and wrote the manuscript.

Jung Yu, Eun Ji Lee, Kuk Bin Ji, Eun Do Lee, Dong Eon Kim, Kang-Sun Park, Eun Young Kim, and Ji Hye Lee contributed to sample preparation and performed the experiment.

Kwang Bae Yoon conceived of the original idea and discussed the results.

Seung-Hwan Lee discussed the results and contributed to the analysis of data and to the final version of the manuscript.
Min Kyu Kim conceived the original idea, discussed the results, supervised the project, and contributed to the final version of the manuscript.

\section{ACKNOWLEDGEMENT}

This study were financially supported by research fund of Chungnam National University at Republic of Korea in 2015, and Environment Protection Division (Grant No. 201300213956) at Inje country office, Injeeup, Inje-gun, Gangwon-do, Republic of Korea.

\section{REFERENCES}

Aramilev, V. V. 2009 Sika deer in Russia. In, Sika Deer. Springer, pp. 475-499

Ba, H., et al. 2015 Classification and phylogeny of sika deer (Cervus nippon) subspecies based on the mitochondrial control region DNA sequence using an extended sample set. Mitochondrial DNA, 26: 373-379

Evanno, G., Regnaut, S. and Goudet, J. 2015 Detecting the number of clusters of individuals using the software STRUCTURE: a simulation study. Molecular ecology, 14: 2611-2620

Harris, R. B. 2015 Cervus nippon. The IUCN Red List of Threatened Species. In. IUCN

Jin, K.-J. 2013 The Analytical Study for Sika Deer's Behaviour Pattern and Characteristics of Their Habitats Through Monitoring the Sika Deer Released at the Urban Forests in South Korea. Korean Journal of Environmental Biology 31: 322-332

Jo, Y.-S. 2015 Texas Tech University; Mammals of Korea: Conservation and management

Koh, H. S., et al. 2010 Species identification of the sika deer in deer farms from Northeast China, North Korea, and Korea, revealed by the sequencing of mitochondrial DNA cytochrome b gene. Bulletin of the Natural Sciences, 24: 7-11

Koh, H. S. and Jin, Y. 2008 Taxonomic Identification of Sika Deer (Cervus nippon Temminck 1838) from Deer Farms in Northeast China and North Korea by the Sequencing of Mitochondrial DNA Cytochrome b Gene. Animal Cells and Systems, 21: 49-53

Krojerova-Prokesova, J., et al. 2013 Dybowski's sika deer (Cervus nippon hortulorum): genetic divergence between natural primorian and introduced Czech populations. The Journal of heredity, 104: 312-326

Lee, Y. S., et al. 2016 Genetic diversity and phylogeography of Siberian roe deer, Caproulus pygargus, in central and peripheral populations. Ecol Evol, 6: 7286-7297

Lu, X. P., et al. 2006 Genetic diversity among Chinese sika deer (Cervus nippon) populations and relationships between Chinese and Japanese sika deer. Chinese Sci Bull, 51: 433-440

McCullough, E. D. R. 2009 Sika deer in Korea and Vietnam. In, Sika Deer. Springer, pp. 541-548

McCullough, E. D. R., Jiang, Z.-G. and Li, C.-W. 2009 Sika deer in mainland China. In, Sika Deer. Springer, pp. 521-539

McDevitt, A. D., et al. 2009 Genetic structure of, and hybridisation between, red (Cervus elaphus) and sika (Cervus nippon) deer in Ireland. Mamm Biol 2009, 74: 263-273

Wang, S., 1998 China. Guo jia huan jing bao hu ju. and Zhonghua Renmin Gongheguo bin wei wu zhong ke xue wei yuan hui. Zhongguo bin wei dong wu hong pi shu. Shou lei. Beijing: Ke xue chu ban she

Whitehead, G. K. 1993 Whitehead encyclopedia of deer. Voyageur Press

Wilson, D. E. and Reeder, D. M. 2005 Mammal species of the world : a taxonomic and geographic reference. Baltimore: Johns Hopkins University Press

Woon, P. 1967 Illustrated encyclopedia of fauna and flora of Korea, Vol. 7, Mammals. In.: Samhwa Publishing Co., Seoul 